SUPPLEMENTARY MATERIAL

Figure 2 The spot shapes in a diamond-affected integration area using masks (above) and full masks (under). The nine matrices represent the "slices" of a cubic integration box around the expected position of the peak. The number represent the expected percentual intensities used to integrate the peaks. As can be clearly seen the first three sections differ strongly in the two cases due to the presence of a diamond reflection almost in correspondence to an expected sample intensity.

\title{
simple masks
}

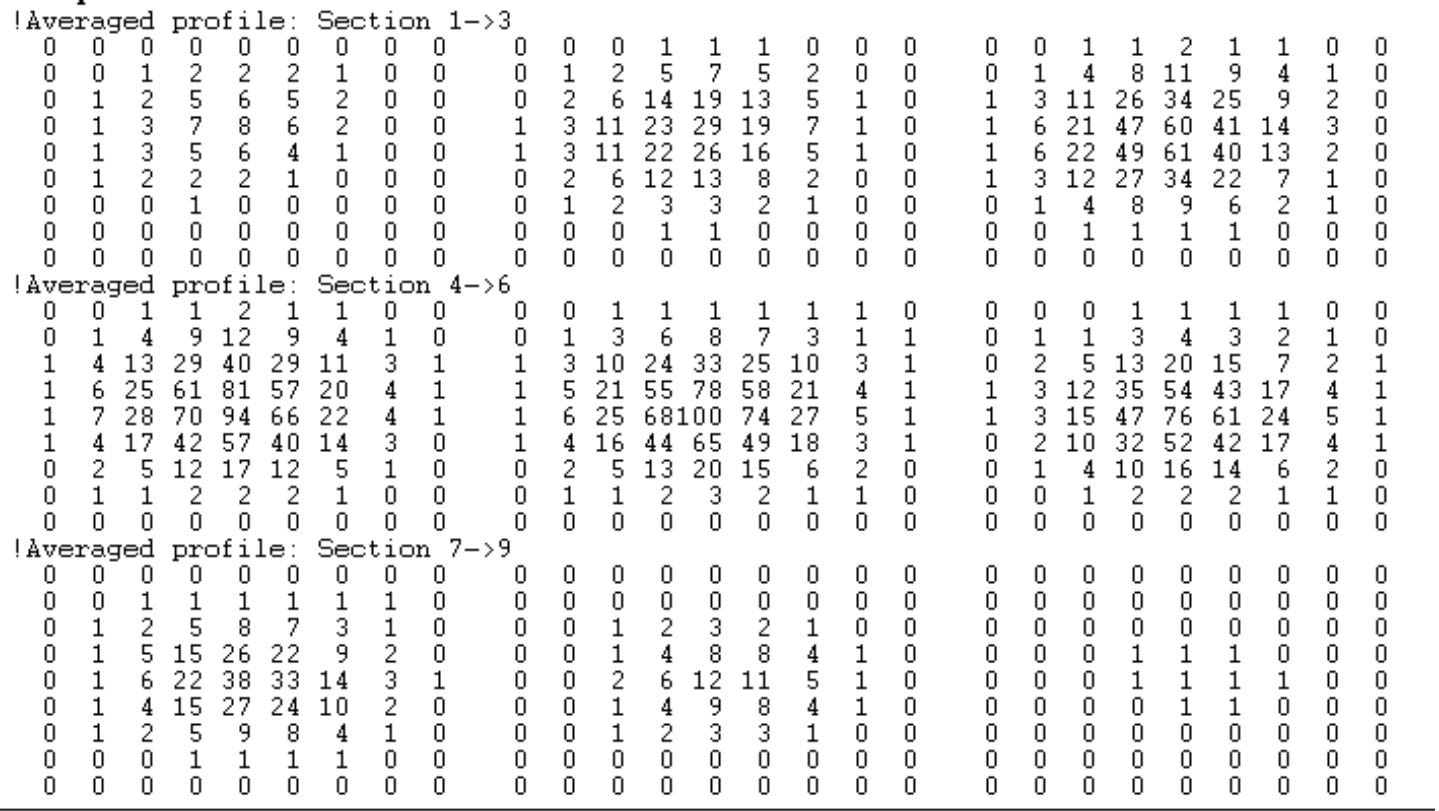

\section{no diamond masks}

\begin{tabular}{|c|c|c|c|c|c|c|c|c|c|c|c|c|c|c|c|c|c|c|c|c|c|c|c|c|c|c|c|}
\hline \multicolumn{3}{|c|}{ ! Averaged } & \multicolumn{3}{|c|}{ profile: } & \multicolumn{4}{|c|}{ Section $1->3$} & \multirow[b]{2}{*}{0} & \multirow[b]{2}{*}{0} & \multirow[b]{2}{*}{0} & \multirow[b]{2}{*}{0} & \multirow[b]{2}{*}{0} & \multirow[b]{2}{*}{0} & \multirow[b]{2}{*}{0} & \multirow[b]{2}{*}{0} & \multirow[b]{2}{*}{0} & \multirow[b]{2}{*}{0} & \multirow[b]{2}{*}{0} & \multirow[b]{2}{*}{0} & \multirow[b]{2}{*}{0} & \multirow{2}{*}{\multicolumn{2}{|c|}{0}} & \multirow[b]{2}{*}{0} & \multirow[b]{2}{*}{0} & \\
\hline 0 & 0 & & 0 & 0 & & 0 & 0 & 0 & 0 & & & & & & & & & & & & & & & & & & \\
\hline 0 & 0 & 0 & 0 & 0 & 0 & 0 & 0 & 0 & 0 & 0 & 0 & 1 & 1 & 0 & 0 & 0 & & 0 & 1 & 1 & 1 & 2 & & & 0 & 0 & 0 \\
\hline 0 & 0 & 0 & 0 & 0 & 0 & 0 & 0 & 0 & 0 & 1 & 2 & 3 & 3 & 2 & 1 & 0 & L & 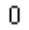 & 1 & 4 & 9 & 11 & & & 2 & 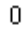 & \\
\hline 0 & 0 & 0 & 1 & 1 & 0 & 0 & 0 & 0 & 0 & 1 & 4 & 8 & 10 & 6 & 2 & 0 & L & 0 & 2 & 10 & 25 & 32 & 2. & & 7 & 1 & \\
\hline 0 & 0 & 1 & 1 & 1 & 0 & 0 & 0 & 0 & 0 & 1 & 5 & 11 & 14 & 8 & 2 & 0 & & & 3 & 12 & 33 & 45 & 3 & & 9 & & \\
\hline 0 & 0 & 0 & 1 & 1 & 0 & 0 & 0 & 0 & 0 & 1 & 3 & 7 & 9 & 6 & 2 & 0 & & & 2 & 8 & 22 & 30 & 2 & & b & & \\
\hline 0 & 0 & 0 & 0 & 0 & 0 & 0 & 0 & 0 & 0 & 0 & 1 & 2 & 3 & 2 & 1 & 0 & & & 1 & 3 & 7 & 9 & & & 2 & & \\
\hline 0 & 0 & 0 & 0 & 0 & 0 & 0 & 0 & 0 & 0 & 0 & 0 & 0 & 0 & 0 & 0 & 0 & 0 & 0 & 0 & 1 & 1 & 1 & & & 0 & 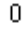 & \\
\hline 0 & 0 & 0 & 0 & 0 & 0 & 0 & 0 & 0 & 0 & 0 & 0 & 0 & 0 & 0 & 0 & 0 & 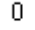 & 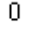 & 0 & 0 & 0 & 0 & & & 0 & 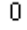 & \\
\hline ! Ave & $\mathrm{ag}$ & $E d$ & pro & $f i$ & & Sed & ic & & & & & & & & & & & & & & & & & & & & \\
\hline 0 & 0 & 0 & 0 & 0 & 0 & 0 & 0 & 0 & 0 & 0 & 0 & 1 & 1 & 0 & 0 & 0 & 0 & 0 & 0 & 0 & 0 & 0 & & & 0 & 0 & \\
\hline 0 & 1 & 2 & 2 & 3 & 2 & 1 & 0 & 0 & 0 & 1 & 2 & 3 & 3 & 2 & 1 & 1 & & 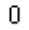 & 1 & 1 & 2 & 3 & & & 1 & 1 & \\
\hline 1 & 2 & 6 & 15 & 19 & 13 & 5 & 1 & 0 & 0 & 2 & 7 & 16 & 22 & 16 & 6 & 1 & 0 & 0 & 1 & 5 & 12 & 17 & 1 & & 5 & 1 & \\
\hline 1 & 3 & 16 & 43 & 59 & 41 & 14 & 2 & 0 & 1 & 3 & 17 & 48 & 70 & 51 & 18 & 3 & 1 & 0 & 2 & 11 & 35 & 55 & 4 & & 16 & 3 & \\
\hline 1 & 4 & 20 & 58 & 84 & 60 & 20 & 3 & 1 & 1 & 4 & 22 & 661 & 100 & 75 & 27 & 4 & 1 & U & 3 & 15 & 49 & 7 & 6 & & 24 & 1 & \\
\hline 1 & 3 & 14 & 39 & 56 & 41 & 14 & 2 & 0 & 1 & 3 & 15 & 44 & 68 & 52 & 19 & 3 & 1 & 0 & 2 & 11 & 34 & 55 & 4 & & 18 & 4 & \\
\hline 0 & 1 & 5 & 12 & 17 & 13 & 5 & 1 & 0 & 0 & 1 & 5 & 14 & 21 & 17 & 7 & 2 & 0 & 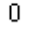 & 1 & 4 & 11 & 17 & 1 & & 6 & 2 & \\
\hline 0 & 1 & 1 & 2 & 2 & 2 & 1 & 0 & 0 & 0 & 1 & 1 & 2 & 3 & 2 & 1 & 1 & 0 & 0 & 0 & 1 & 2 & 2 & & & 1 & 1 & \\
\hline 0 & 0 & 0 & 0 & 0 & 0 & 0 & 0 & 0 & 0 & 0 & 0 & 0 & 0 & 0 & 0 & 0 & 0 & 0 & 0 & 0 & 0 & 0 & & & 0 & 0 & \\
\hline $\mathrm{ve}$ & & & pro & $i$ & & Sec & ic & & & & & & & & & & & & & & & & & & & & \\
\hline 0 & 0 & 0 & 0 & 0 & 0 & 0 & 0 & 0 & 0 & 0 & 0 & 0 & 0 & 0 & 0 & 0 & & 0 & 0 & 0 & 0 & 0 & & & 0 & 0 & \\
\hline 0 & 0 & 1 & 1 & 1 & 1 & 1 & 0 & 0 & 0 & 0 & 0 & 0 & 0 & 0 & 0 & 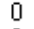 & 0 & 0 & 0 & 0 & 0 & 0 & & & 0 & 0 & \\
\hline 0 & 1 & 2 & 6 & 9 & 7 & 3 & 1 & 0 & 0 & 0 & 1 & 2 & 3 & 2 & 1 & 0 & 0 & 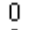 & 0 & 0 & 0 & 0 & & & 0 & & \\
\hline 0 & 1 & 5 & 17 & 28 & 23 & 10 & 2 & 0 & 0 & 0 & 1 & 4 & 8 & 8 & 4 & 1 & & 0 & 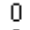 & 0 & 1 & & & & 1 & & \\
\hline 0 & 1 & 7 & 24 & 41 & 35 & 14 & 3 & 1 & 0 & 0 & 2 & 6 & 12 & 11 & 5 & 1 & 0 & 0 & 0 & 0 & 1 & 1 & & & 1 & U & \\
\hline 0 & 1 & 5 & 17 & 29 & 25 & 11 & 2 & 0 & 0 & 0 & 1 & 5 & 9 & 8 & 4 & 1 & 0 & 0 & 0 & 0 & 1 & 1 & & & 1 & 0 & \\
\hline 0 & 1 & 2 & 6 & 9 & 8 & 4 & 1 & 0 & 0 & 0 & 1 & 2 & 3 & 3 & 1 & 0 & 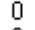 & 0 & 0 & 0 & 0 & 0 & & & 0 & 0 & \\
\hline 0 & 0 & 1 & 1 & 1 & 1 & 1 & 0 & 0 & 0 & 0 & 0 & 0 & 0 & 0 & 0 & 0 & 0 & & 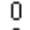 & 0 & 0 & 0 & & & 0 & & \\
\hline 0 & 0 & 0 & 0 & 0 & 0 & 0 & 0 & 0 & 0 & 0 & 0 & 0 & 0 & 0 & 0 & 0 & 0 & 0 & 0 & 0 & 0 & 0 & & & 0 & 0 & \\
\hline
\end{tabular}

